\title{
Sorafenib and a novel immune therapy in lung metastasis from hepatocellular carcinoma following hepatectomy: A case report
}

\author{
YONGXIANG YI ${ }^{1}$, JIANBO HAN $^{1 *}$, YUAN FANG $^{2 *}$, DONGXIAO LIU $^{1 *}$, \\ ZUOYOU WU $^{1}$, LILI WANG ${ }^{3}$, LIANG ZHAO ${ }^{1}$ and QIANG WEI $^{4}$ \\ Departments of ${ }^{1}$ Hepatobiliary Surgery and ${ }^{2}$ Pathology, ${ }^{3}$ Biological Treatment Center, ${ }^{4}$ Department of Ultrasonography, \\ The Second Affiliated Hospital of Southeast University, Nanjing, Jiangsu 210003, P.R. China
}

Received November 19, 2015; Accepted April 8, 2016

DOI: $10.3892 / \mathrm{mco} .2016 .925$

\begin{abstract}
Sorafenib is the standard therapeutic strategy for recurrent hepatocellular carcinoma (HCC) following hepatectomy. However, only few patients truly benefit from this therapy. Thus, new strategies combined with sorafenib are urgently required. We herein present the case of a patient with hepatic and extrahepatic HCC recurrence following hepatectomy, who was treated by combined sorafenib, focused ultrasound knife and DRibbles-pulsed dendritic cell (DC) vaccine. Enzyme-Linked ImmunoSpot assay (ELISPOT) and intracellular staining (ICS) analysis were used to detect the secretion of interferon (IFN) $-\gamma$ by $\mathrm{T}$ cells at different timepoints of the vaccine in order to evaluate the patient's specific T-cell response to SMMC-7721-derived DRibbles vaccine. The $\alpha$-fetoprotein level decreased from 103,295 to $5 \mathrm{ng} / \mathrm{ml}$ and the patient displayed improved liver function, an Eastern Cooperative Oncology Group performance status score of 0 , remission of liver metastases and disappearance of the lung metastases 8 months post-combination therapy. The computed tomography scan revealed the disappearance of liver metastases 2 years post-combination therapy. The ELISPOT data revealed a low antigen-specific T-cell response 4 weeks after the first vaccine cycle and the response decreased to nearly zero prior to the second cycle. However, high antigen-specific T-cell response was observed 2 weeks after the second vaccine cycle and did not decrease, even after 10 months, which was consistent with the result of the ICS analysis, which demonstrated that most of the secreted IFN- $\gamma$ was produced by $\mathrm{CD} 4^{+} \mathrm{T}$ cells, whereas a low $\mathrm{CD} 8^{+} \mathrm{T}$-cell response was observed (0.429 vs. $0.0665 \%$, respectively). Our results demonstrated that antigen-specific T-cell response
\end{abstract}

Correspondence to: Dr Yongxiang Yi, Department of Hepatobiliary Surgery, The Second Affiliated Hospital of Southeast University, 1-1 Zhongfu Road, Nanjing, Jiangsu 210003, P.R. China

E-mail: ian0126@126.com

*Contributed equally

Key words: recurrent hepatocellular carcinoma, lung metastasis, sorafenib, immune therapy aimed to treat recurrent $\mathrm{HCC}$ may be induced through stimulation by the DC-DRibbles vaccine. The success of the treatment supports the combination of sorafenib, focused ultrasound knife and DC-DRibbles vaccine as a therapeutic strategy for patients with $\mathrm{HCC}$ recurrence following hepatectomy.

\section{Introduction}

Hepatocellular carcinoma (HCC) is the fifth most common type of cancer and the second most common cause of cancer-related mortality worldwide (1). Curative resection or liver transplantation is recommended for early-stage HCC, with a reported 5-year survival of $>50 \%$ (2). However, a considerable proportion of patients may develop HCC recurrence and the survival of such patients is very poor, as recurrent tumors are usually aggressive and unresectable (3). Moreover, HCC is significantly resistant to radio- or chemotherapy, the standard of care in the majority of advanced tumors (2).

Although the multikinase inhibitor sorafenib was approved for the treatment of advanced HCC in 2008, there remain issues regarding the management of this disease $(4,5)$. In particular, this therapy exhibits wide variability in terms of prolongation of patient survival, and only few patients truly benefit from this therapy. Combination therapy with sorafenib and other modalities, such as transarterial chemoembolization or everolimus, has been investigated, with some benefits (6-8).

A novel vaccine strategy for producing DRibbles, whose major structure and functional constituents are autophagosomes, has been developed (9). DRibbles has been found to be significantly efficient in stimulating human antigen-specific CD8 memory T cells ex vivo and DRibbles-pulsed dendritic cell (DC) immunization may induce T-cell response against HCC and result in significant inhibition of tumor growth in mice $(10,11)$. We herein report the case of a patient with lung metastasis from HCC following hepatectomy, who was treated with combination therapy with sorafenib, focused ultrasound knife and DC-DRibbles vaccine and achieved complete response.

\section{Case report}

A 42-year old male patient, who was diagnosed with primary HCC associated with hepatitis B virus infection, underwent 

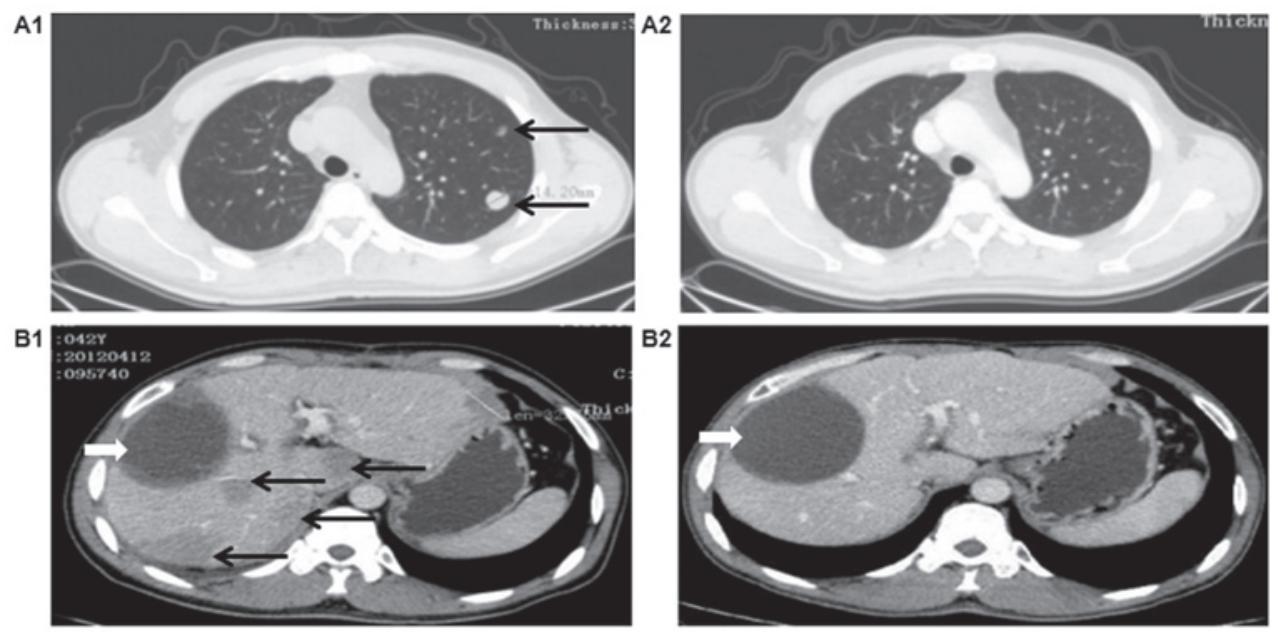

Figure 1. Computed tomography response to combination treatment with DC-DRibbles vaccine, sorafenib and focused ultrasound knife. Prior to combination treatment, on April, 2012, (A1) multiple pulmonary metastases were identified (arrows) and (B1) an intrahepatic giant hepatocellular carcinoma (HCC), with multifocal, bilobar HCC recurrence following curative hepatectomy found in the liver (black arrows, recurrence of HCC; white arrow, change after hepatectomy). Following combination treatment, a complete response was observed, with (A2) disappearance of lung metastases by December, 2012 and (B2) disappearance of liver metastases by June, 2015.

curative hepatectomy in February, 2012. Enhanced computed tomography (CT) findings revealed an intrahepatic giant HCC in the right lobe of the liver, which was $100 \mathrm{~mm}$ in diameter. No preoperative biopsy of the liver mass was conducted and HCC was diagnosed according to radiological criteria (12). At the time of the diagnosis, the patient presented with a good liver function reserve (Child-Turcotte-Pugh class A). The $\alpha$-fetoprotein (AFP) serum level was 18,408.27 ng/ml (normal level, $10 \mathrm{ng} / \mathrm{ml}$ ). Based on the Barcelona Clinical Liver Cancer (BCLC) staging system, the tumor was BCLC stage B, and the Eastern Cooperative Oncology Group (ECOG) performance status score was 1 according to the general assessment. The primary tumor was removed and it was found to be a G2-G3 $\mathrm{HCC}$, without hepatic portal lymphatic metastasis. In addition, no portal vein thrombosis was detected.

Less than 2 months after surgery, recurrence of multiple, bilateral liver lesions was observed on CT, of which the largest was $85 \times 69 \mathrm{~mm}$ in size, while simultaneous multiple pulmonary metastases were observed in the lower part of the left lung. In accordance with the recurrence of HCC, the AFP level increased to $37,202.46 \mathrm{ng} / \mathrm{ml}$. In April, 2012, considering the presence of intra- and extrahepatic metastases, the patient was placed on sorafenib (Nexavar, Bayer) at a dosage of $400 \mathrm{mg}$ b.i.d.; grade 1 hand-foot syndrome developed. One month after the administration of sorafenib, the AFP level increased to $103,295 \mathrm{ng} / \mathrm{ml}$; thus, focused ultrasound knife therapy for the liver lesions was repeated 7 times. At the same time, DC-DRibbles biotherapy was administered as follows: The patient underwent apheresis to obtain peripheral blood mononuclear cells (PBMCs), which were cultured for 3-5 days with granulocyte-macrophage colony-stimulating factor (GM-CSF) and interferon (IFN)- $\alpha$ to obtain IFN-DC on day 0 (13). IFN-DCs were administered by subcutaneous injection ( $10^{7}$ cells each time) on days 4,18 and 31 . HCC cell line SMMC-7721-derived DRibbles was prepared as previously described (14). Briefly, SMMC-7721 cells were treated with bortezomib $(200 \mathrm{nmol} / \mathrm{l})$ and ammonium chloride (10-20 mmol/l) for 24-48 h. DRibbles was dislodged from cells or large cell debris by rigorous pipetting. The suspension was then centrifuged at $10,000 \mathrm{x} g$ to harvest DRibbles. The total amount of protein in DRibbles was quantified by a bicinchoninic acid protein assay kit according to the manufacturer's protocol (Thermo Scientific, Rockford, IL, USA). The SMMC-7721 derived DRibbles ( $250 \mu$ g each time) was administered to the inguinal lymph nodes (LNs) bilaterally under ultrasound guidance, for a total of three times, separated by 2 -week intervals.

In June, 2012, a boost immunization of DC-DRibbles vaccine was performed. DC was cultured in the same way as in the first cycle and was loaded with DRibbles in vitro, DC-DRibbles $\left(10^{7}\right.$ cells each time) were administered subcutaneously in the area of the inguinal LNs bilaterally, for a total of 3 times, with 3-day intervals. On clinical evaluation, no short-term or long-term toxicity was observed and the patient exhibited adequate liver function and no signs of portal hypertension throughout the entire duration of the follow-up.

In December, 2012, 8 months post-combination therapy, the AFP level returned to normal, the patient had normal liver function (Child-Pugh class A) and an ECOG score of 0. Surprisingly, the CT scan revealed remission of the liver metastases and disappearance of the lung metastases, which was a significant improvement compared with the scan in April, 2012 (Fig. 1A1 and A2). The liver metastases had disappear completely on the CT scan in June, 2015 (Fig. 1B1 and B2).

As a traditional indicator for evaluating the curative effect and recurrence of HCC, the level of serum AFP was measured every 1-2 months (Fig. 2) and was found to be transiently decreased after the initial surgical treatment, but swiftly increased to $37,202.46 \mathrm{ng} / \mathrm{ml}$ upon recurrence of HCC, as demonstrated by $\mathrm{CT}$ scan. Following combined treatment with DC-DRibbles vaccine, sorafenib and focused ultrasound knife, the level of serum AFP decreased significantly and returned to normal.

To evaluate the patient's specific T-cell response to SMMC-7721-derived DRibbles vaccine, ELISPOT and intracellular staining (ICS) analysis were performed to detect 


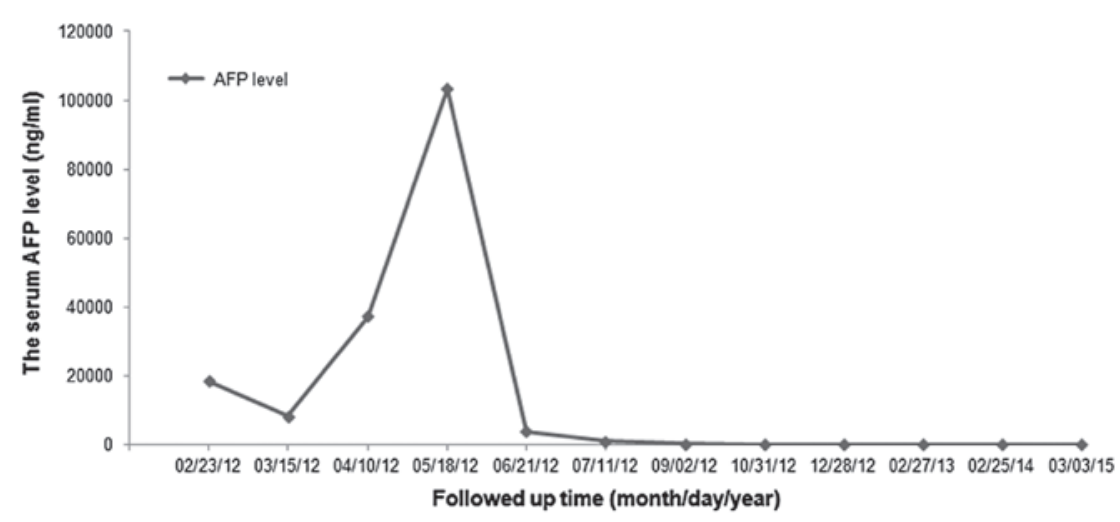

Figure 2. Dynamic observation of the level of serum $\alpha$-fetoprotein (AFP) along with the progression of hepatocellular carcinoma.

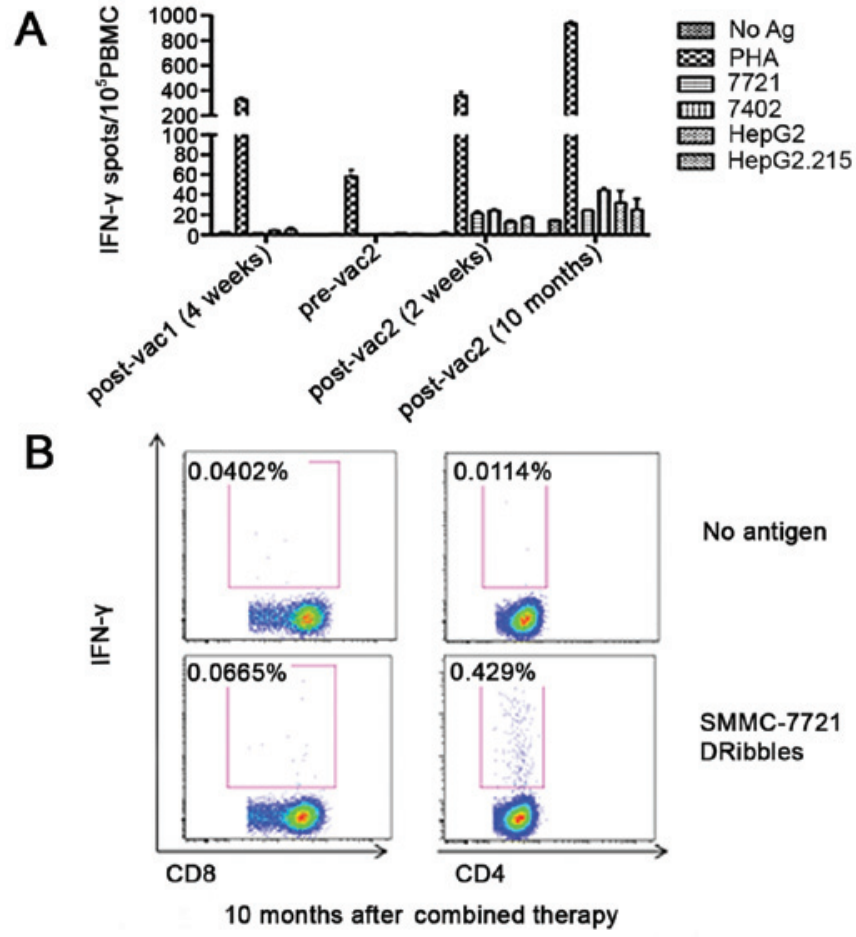

Figure 3. Antigen-specific T-cell response to DC-DRibbles vaccine. (A) Enzyme-Linked ImmunoSpot assay analysis restimulated by DRibbles derived from different hepatocellular carcinoma cell lines shows that there was a low antigen-specific T-cell response after the first cycle of DC-DRibbles vaccine, whereas a high response was observed after the second cycle of the vaccine combined with sorafenib and focused ultrasound knife. (B) Intracellular staining analysis restimulated by SMMC-7721-derived DRibbles shows that a high $\mathrm{CD}^{+}$and low $\mathrm{CD} 8^{+} \mathrm{T}$-cell response was observed at the timepoint of 10 months after combination therapy. IFN, interferon; PBMC, peripheral blood mononuclear cell.

the secretion of IFN- $\gamma$ by T cells at different timepoints, as shown in Fig. 3. Briefly, PBMCs were isolated from fresh blood by density gradient centrifugation in Ficoll solution and seeded into a 96-well plate. DRibbles derived from different liver tumor cell lines (SMMC-7721, BEL-7402, HepG2 and HepG2.215) were pulsed with PBMCs to restimulate T cells at the concentration of $25 \mu \mathrm{g} / \mathrm{ml}$; the no antigen group served as negative control and the phytohemagglutinin group as positive control. After stimulation, ELISPOT and ICS analysis were conducted according to the standard protocol. The ELISPOT data showed a low antigen-specific T-cell response 4 weeks after the first vaccine cycle and the response decreased to nearly zero prior to the second cycle. However, high antigen-specific T-cell response was observed 2 weeks after the second vaccine cycle and did not decrease even after 10 months, which was consistent with the result of the ICS analysis. In addition, the ICS results demonstrated that most of the secretory of IFN- $\gamma$ was produced by $\mathrm{CD}^{+} \mathrm{T}$ cells, whereas a low $\mathrm{CD} 8^{+} \mathrm{T}$-cell response was observed ( 0.429 vs. $0.0665 \%$, respectively).

Eight months after combined treatment with DC-DRibbles vaccine, sorafenib and focused ultrasound knife, a response of $87 \%$ according to the modified Response Evaluation Criteria in Solid Tumors (mRECIST) (15) was observed on CT, with a change in total diameter of contrast-enhanced areas in targeted tumor nodules from $311.81 \mathrm{~cm}$ (in 12 nodules) to $29.37 \mathrm{~cm}$ (in 2 nodules). Three years after the combined treatment, the tumor nodules had disappeared completely in the lung and liver, according to the CT scan.

Three years after the diagnosis of metastases and post-combined therapy, the AFP serum level remains within the normal range. Additionally, the enhanced CT scan has not revealed any new recurrence and the patient remains Child-Pugh A and ECOG 0. Treatment with sorafenib has been continued and a follow-up program to evaluate the duration of the response of this combination therapy is in progress. The patient also maintains a relatively active lifestyle and no additional adverse events have been reported.

Written informed consent was obtained from the patient in accordance with the Declaration of Helsinki. The treatment protocol was approved by the Human Research Ethics Committee of the Second Affiliated Hospital of Southeast University.

\section{Discussion}

The main therapeutic option for advanced-stage HCC is sorafenib, an oral inhibitor of the vascular endothelial growth factor receptor, the platelet-derived growth factor receptor, and Raf. Sorafenib has been proven to prolong the survival of patients with advanced HCC over placebo in the SHARP and the Asian-Pacific pivotal studies $(4,5)$. However, only a small proportion of patients truly benefited from sorafenib treatment, and an even smaller percentage of treated patients achieves partial or complete response according to the RECIST criteria 
on follow-up examinations. Thus, novel therapeutic strategies containing sorafenib are urgently needed.

Autophagy is a basic cellular mechanism of degrading cytoplasmic proteins and organelles and functions as a homeostatic process in eukaryotic cells (16). Autophagosomes are double-layered membrane structures produced in the process of the sequestration of cytoplasmic components. Our studies demonstrated that antigens sequestered in the autophagosome may be delivered to DCs for cross-presentation and prime naïve antigen-specific CD8 T cells effectively (17). Subsequently, autophagosomes containing a broad spectrum of cellular antigens from antigen donor cells were collected by induction of autophagy and inhibition of lysosomal/proteosomal activity, and named DRibbles $(9,14,18,19)$. DRibbles have been demonstrated to exhibit vigorous antitumor efficacy in mouse experiments and cross-prime human CD8 T cells in ex vivo studies $(10,11)$. In this study, we extracted DRibbles from the HCC cell line SMMC7721 and injected them into the inguinal LNs bilaterally in HCC patients. The results of flow cytometry, ICS and ELISPOT demonstrated that tumor antigen-specific CD4 and CD8 T cells could be primed in the human body. As DRibbles were used as stimulating antigens in the detection, the exact antigen-specific T-cell epitopes could not be identified.

Cross-presentation is crucial for the activation of CD8 $\mathrm{T}$ cells primed by exogenous antigens (20). DCs are the most potent professional antigen-presenting cells (pAPCs) in humans. In this study, LN DCs and monocyte-derived DCs were used as pAPCs to cross-present DRibbles antigens. In vivo cross-presentation occurs in secondary lymphoid organs, particularly LNs containing mature $\mathrm{CD}^{+} \mathrm{c}^{+}$conventional DCs (cDCs), CD141 ${ }^{+}$cDCs, and plasmacytoid DCs (21). SMMC7721-DRibbles was injected directly into the inguinal LNs bilaterally. We hypothesize that LN DC subsets may internalize and degrade DRibbles and display the resulting peptides on their cell surface during the process of cross-presentation. Recently, CLEC9A was shown to recognize dead cell-associated antigen and play a critical role in cross-presentation of antigens from necrotic cells $(22,23)$. DRibbles was found to express abundant CLEC9A ligand and may directly bind to CLEC9A expressed on the surface of CD141 ${ }^{+} \mathrm{cDC}$ subsets. This suggests that the $\mathrm{CD} 141^{+} \mathrm{cDC}$ subset may be involved in the recognition or subsequent procession of DRibbles by DCs (14). In the presence of GM-CSF and IFN- $\alpha$, monocytes may differentiate into IFN-DCs in vitro, which may have a more potent function in terms of CD8 T-cell cross-priming compared with traditional interleukin (IL)-4-DCs generated from monocytes stimulated by GM-CSF and IL-4 $(13,24)$. It was previously demonstrated that IFN-DCs may cross-present DRibbles and prime human memory antigen-specific CD8 and CD4 T cells more effectively compared with IL-4-DCs (data not shown). Consequently, the IFN-DC-DRibbles vaccine strategy was also implemented in our patient. The results demonstrated that antigen-specific CD8 and CD4 T cells may be activated, but we were unable to discriminate the type of DCs playing the major role between LN DCs and IFN-DCs.

In the present case, the sorafenib-DC-DRibbles combination led to complete tumor response, whereas no serious side effects were observed. We hypothesize that there is a synergistic action of these two therapeutic strategies, as the exact mechanism could not be illustrated exactly. The success of the treatment in the present case supports the value of combined strategy of targeted therapy and immunological therapy in patients with recurrent $\mathrm{HCC}$.

\section{Acknowledgements}

The present study was supported by grants from the Nanjing Medical Science and Technique Development Foundation, Nanjing Department of Health (nos. QRX11235 and ZDX12008) and the Jiangsu Provincial Clinical Medical Science and Technology project (no. BL2014005).

\section{References}

1. Au JS and Frenette CT: Management of hepatocellular carcinoma: Current status and future directions. Gut Liver 9: 437-448, 2015.

2. Colagrande $S$, Regini $F$, Taliani GG, Nardi $C$ and Inghilesi AL: Advanced hepatocellular carcinoma and sorafenib: Diagnosis, indications, clinical and radiological follow-up. World $\mathrm{J}$ Hepatol 7: 1041-1053, 2015

3. Takeishi K, Maeda T, Tsujita E, Yamashita Y, Harada N, Itoh S, Harimoto N, Ikegami T, Yoshizumi T, Shirabe K and Maehara Y: Predictors of intrahepatic multiple recurrences after curative hepatectomy for hepatocellular carcinoma. Anticancer Res 35: 3061-3066, 2015

4. Llovet JM, Ricci S, Mazzaferro V, Hilgard P, Gane E, Blanc JF, de Oliveira AC, Santoro A, Raoul JL, Forner A, et al: Sorafenib in advanced hepatocellular carcinoma. N Engl J Med 359: 378-390, 2008.

5. Cheng AL, Kang YK, Chen Z, Tsao CJ, Qin S, Kim JS, Luo R, Feng J, Ye S, Yang TS, et al: Efficacy and safety of sorafenib in patients in the Asia-Pacific region with advanced hepatocellular carcinoma: A phase III randomised, double-blind, placebo-controlled trial. Lancet Oncol 10: 25-34, 2009.

6. Pawlik TM, Reyes DK, Cosgrove D, Kamel IR, Bhagat N and Geschwind JF: Phase II trial of sorafenib combined with concurrent transarterial chemoembolization with drug-eluting beads for hepatocellular carcinoma. J Clin Oncol 29: 3960-3967, 2011.

7. Han G, Yang J, Shao G, Teng G, Wang M, Yang J, Liu Z, Feng G, Yang R, Lu L, et al: Sorafenib in combination with transarterial chemoembolization in Chinese patients with hepatocellular carcinoma: A subgroup interim analysis of the START trial. Future Oncol 9: 403-410, 2013.

8. Bhoori S, Toffanin S, Sposito C, Germini A, Pellegrinelli A, Lampis A and Mazzaferro V: Personalized molecular targeted therapy in advanced, recurrent hepatocellular carcinoma after liver transplantation: A proof of principle. J Hepatol 52: 771-775, 2010.

9. Yi Y, Zhou Z, Shu S, Fang Y, Twitty C, Hilton TL, Aung S, Urba WJ, Fox BA, Hu HM and Li Y: Autophagy-assisted antigen cross-presentation: Autophagosome as the argo of shared tumor-specific antigens and DAMPs. Oncoimmunology 1: 976-978, 2012.

10. Ye W, Xing Y, Paustian C, van de Ven R, Moudgil T, Hilton TL, Fox BA, Urba WJ, Zhao W and Hu HM: Cross-presentation of viral antigens in dribbles leads to efficient activation of virus-specific human memory T cells. J Transl Med 12: 100, 2014.

11. Su S, Zhou H, Xue M, Liu JY, Ding L, Cao M, Zhou ZX, Hu HM and Wang LX: Anti-tumor efficacy of a hepatocellular carcinoma vaccine based on dendritic cells combined with tumor-derived autophagosomes in murine models. Asian Pac J Cancer Prev 14: 3109-3116, 2013.

12. Bruix J and Sherman M; Practice Guidelines Committee, American Association for the Study of Liver Diseases: Management of hepatocellular carcinoma. Hepatology 42: 1208-1236, 2005.

13. Lapenta C, Santini SM, Spada M, Donati S, Urbani F, Accapezzato D, Franceschini D, Andreotti M, Barnaba V and Belardelli F: IFN-alpha-conditioned dendritic cells are highly efficient in inducing cross-priming $\mathrm{CD} 8^{+} \mathrm{T}$ cells against exogenous viral antigens. Eur J Immunol 36: 2046-2060, 2006. 
14. Li Y, Wang LX, Pang P, Cui Z, Aung S, Haley D, Fox BA, Urba WJ and Hu HM: Tumor-derived autophagosome vaccine: Mechanism of cross-presentation and therapeutic efficacy. Clin Cancer Res 17: 7047-7057, 2011.

15. Eisenhauer EA, Therasse P, Bogaerts J, Schwartz LH, Sargent D, Ford R, Dancey J, Arbuck S, Gwyther S, Mooney M, Rubinstein L, Shankar L, Dodd L, Kaplan R, Lacombe D and Verweij J: New response evaluation criteria in solid tumours: revised RECIST guideline (version 1.1). Eur J Cancer 45: 228-247, 2009.

16. Choi AM, Ryter SW and Levine B: Autophagy in human health and disease. N Engl J Med 368: 1845-1846, 2013.

17. Li Y, Wang LX, Yang G, Hao F, Urba WJ and Hu HM: Efficient cross-presentation depends on autophagy in tumor cells. Cancer Res 68: 6889-6895, 2008

18. Li Y, Hahn T, Garrison K, Cui ZH, Thorburn A, Thorburn J, $\mathrm{Hu} \mathrm{HM}$ and Akporiaye ET: The vitamin E analogue $\alpha$-TEA stimulates tumor autophagy and enhances antigen cross-presentation. Cancer Res 72: 3535-3545, 2012

19. Twitty CG, Jensen SM, Hu HM and Fox BA: Tumor-derived autophagosome vaccine: Induction of cross-protective immune responses against short-lived proteins through a p62-dependent mechanism. Clin Cancer Res 17: 6467-6481, 2011.

20. Segura E and Amigorena S: Cross-presentation by human dendritic cell subsets. Immunol Lett 158: 73-78, 2014.

21. Boltjes A and van Wijk F: Human dendritic cell functional specialization in steady-state and inflammation. Front Immunol 5: 131, 2014.
22. Schreibelt G, Klinkenberg LJ, Cruz LJ, Tacken PJ, Tel J, Kreutz M, Adema GJ, Brown GD, Figdor CG and de Vries IJ: The C-type lectin receptor CLEC9A mediates antigen uptake and (cross-)presentation by human blood $\mathrm{BDCA}^{+}$myeloid dendritic cells. Blood 119: 2284-2292, 2012.

23. Poulin LF, Salio M, Griessinger E, Anjos-Afonso F, Craciun L, Chen JL, Keller AM, Joffre O, Zelenay S, Nye E, et al: Characterization of human DNGR $-1^{+} \mathrm{BDCA} 3^{+}$leukocytes as putative equivalents of mouse CD8alpha ${ }^{+}$dendritic cells. J Exp Med 207: 1261-1271, 2010.

24. Ng D and Gommerman JL: The Regulation of Immune Responses by DC Derived Type I IFN. Front Immunol 4: 94, 2013. 